\title{
Pengaruh Financial Slack, Innovational Slack, dan Managerial Slack terhadap Nilai Perusahaan Perdana dengan Kualitas Pelaporan Keuangan sebagai Variabel Moderasi
}

\author{
Setiafitrie Yuniarti, Lindawati Gani, dan Gede Harja Wasistha \\ Program Magister Pascasarjana Ilmu Akuntansi, Fakultas Ekonomi Universitas Indonesia, \\ Depok. Jawa Barat, 16424, Indonesia \\ E-mail:setiafitrie.yuniarti@ui.ac.id, lgani@ui.ac.id,wasistha@ui.ac.id
}

\begin{abstract}
Abstrak
Penelitian ini menganalisis pengaruh tiga jenis slack resources (financial slack, innovational slack, dan managerial slack) terhadap nilai perusahaan perdana atau IPO value yang diukur dengan jumlah proceeds pada saat IPO serta discretionary current accruals sebagai variabel moderasi dalam mengukur kualitas pelaporan keuangan. Enam puluh dua sampel diuji dari 4 sektor industri (basic industry \& chemicals, agriculture, others, dan trade, services \& investment) dengan menggunakan metode regresi linear berganda. Hasil analisis menunjukkan bahwa Innovational Slack memiliki pengaruh positif dan non-linear negatif (U-Terbalik) terhadap nilai perusahaan perdana. Working capital slack tidak memiliki pengaruh terhadap IPO value. Cash reserve slack memiliki pengaruh positif dan experience slack memiliki pengaruh negatif terhadap nilai perusahaan perdana. Discretionary current accruals mempengaruhi secara negatif hubungan cash reserves slack terhadap nilai perusahaan perdana. Berkebalikan dengan hipotesis yang diajukan, jumlah executives slack memiliki pengaruh negatif dan non-linear positif (Berbentuk U) terhadap nilai perusahaan perdananya
\end{abstract}

Kata kunci: Financial Slack; Innovational Slack; Managerial Slack; Discretionary Current Accruals; Nilai Perusahaan Perdana

\section{The Effects of Financial Slack, Innovational Slack, and Managerial Slack on IPO Value with Financial Reporting Quality as Moderating Variable}

\begin{abstract}
This study examines the impact of three types of slack resources (financial slack, innovational slack, and managerial slack) on IPO Value, measured by the amount of proceeds gained at the time of IPO and discretionary current accruals as moderating variable in measuring financial reporting quality By using multiple linear regression method, 62 sample tested from four different sectors (basic industry \& chemicals, agriculture, others, and trade, services \& investment). Analysis result shows that innovational slack has positive and negative non-linear effects (Reversed-U-Shape) on IPO Value. Working capital slack has no effect on IPO value. Cash reserve slack has positive effect but experience slack has negative effect on IPO Value. Discretionary current accruals has negative effect in the relationship of cash reserves slack to IPO value while working capital slack still has no effect on IPO value. Contrary to hypotheses, executives slack has negative and positive non-linear effect (U-Shape) on the IPO Value.
\end{abstract}

Keywords: Financial Slack; Innovational Slack; Managerial Slack; Discretionary Current Accruals; IPO Value.

\section{Pendahuluan}

IPO atau penawaran saham perdana merupakan peristiwa yang sangat penting bagi perusahaan. Prosesnya dapat memberikan banyak tantangan bagi perusahaan dan manajer khususnya dikarenakan bahwa proses tersebut dapat berlangsung dari beberapa bulan sampai 
beberapa tahun, di saat manajemen tidak dapat berfokus sepenuhnya hanya pada pengelolaan bisnis (Andrews \& Welbourne, 2000). Selain mereka harus mengelola operasi kegiatan perusahaan, mereka juga harus mempersiapkan prospektus yang memberikan informasi kepada investor dan publik mengenai perusahaan mereka dan harus terus mempromosikan perusahaan untuk menghasilkan kebutuhan/permintaan saham yang diperlukan. Perusahaan juga menghadapi resource constraints selama proses IPO dan selama perusahaan go public. Maka dari itu, penting untuk menilai resources mana yang paling berguna untuk keberhasilan IPO (Moussa 2009).

Slack resources merupakan kuantitas dinamis yang menunjukkan perbedaan antara current resources perusahaan dengan current resource demands terhadap perusahaan (Mishina, Pollock, dan Porac, 2004). Slack resurces dapat dialihkan atau digunakan kembali untuk mencapai tujuan organisasi (George, 2005). Slack resources bertindak sebagai insentif untuk bereksperimen, mengambil risiko dan membuat pilihan strategis secara proaktif dan bertindak sebagai buffers dalam periode krisis ekonomi (George, 2005).

Penrose (1959) berpendapat bahwa suatu perusahaan terdiri dari bundle of resources yang berpotensi berkontribusi pada posisi kompetitif perusahaan jika valuable services dari resources tersebut dibuat tersedia bagi perusahaan (Newbert, 2007). Dari perspektif resourcebased view (RBV), valuable slack resources dapat memberikan keuntungan kompetitif bagi perusahaan yang melakukan IPO dan, maka dari itu, merupakan jaminan untuk kinerja keuangan yang lebih baik. Penelitian ini berfokus pada slack resources yang dapat bertindak sebagai mekanisme signaling yang kredibel, yang memungkinkan investor dapat membedakan antara IPO berkualitas tinggi dengan IPO yang berkualitas rendah.

Penelitian ini mengkhususkan pada tipe financial slack, innovational dan managerial slack yang digunakan oleh Moussa (2009) yang menyesuaikannya dalam konteks IPO yakni financial, innovational, dan managerial slack. Tipe slack resources ini dianggap penting bagi keberhasilan suatu perusahaan dan survivabiity perusahaan.

Kualitas pelaporan keuangan di Indonesia merupakan kualitas pelaporan keuangan informatif (Fanani 2006). Laba yang ada di dalam laporan keuangan, khususnya pada prospektus IPO, dianggap lebih memberikan informasi bagi investor walaupun manajemen memanipulasi akrual secara opportunistic. Subramanyam (1996) menemukan bahwa kualitas pelaporan keuangan memiliki pengaruh positif terhadap harga saham. Discretionary accruals menandakan kualitas pelaporan keuangan yang rendah. Semakin tinggi disretionary accruals maka semakin tinggi indikasi adanya manipulasi akrual di dalam laporan keuangan untuk meningkatkan laba yang diinginkan. 
Penelitian ini ingin menguji apakah discretionary current accrual dapat memperlemah pengaruh financial slack terhadap nilai perusahaan perdana. Dikarenakan konteks IPO yang unik dan masih belum banyaknya penelitian yang menguji hubungan ini maka Penelitian ini ingin meneliti hubungan slack resources terhadap nilai perusahaan perdana dengan kualitas pelaporan keuangan (discretionary current accruals) sebagai variabel moderasi.

Hasil penelitian ini menunjukkan bahwa working capital slack tidak memiliki pengaruh terhadap nilai perusahaan perdana. Cash reserves slack justru memiliki pengaruh positif terhadap nilai perusahaan perdana. Jika diinteraksikan dengan discretionary current accrual sebagai proksi kualitas pelaporan keuangan, cash reserves slack memberikan pengaruh negatif terhadap nilai perusahaan perdana. Cash reserves slack dari kualitas pelaporan keuangan yang rendah dianggap menunjukkan potensi penyalahgunaan cash reserves slack untuk kepentingan pribadi manajemen. Excess cash juga memperburuk agency problems yang ada antara external stakeholder dengan pemegang saham (Sun et al. 2012) $R \& D$ Slack sebagai innovational slack memiliki pengaruh positif serta non-linear terhadap nilai perusahaan perdana. Sampai pada besaran tertentu $R \& D$ slack dapat meningkatkan perolehan dana hasil IPO namun setelah melebihi besaran tersebut $R \& D$ slack justru memiliki pengaruh negatif terhadap nilai perusahaan perdananya. Hasil ini sesuai dengan penelitian Nohria \& Gulati (1996) Executives' slack memiliki pengaruh negatif terhadap nilai perusahaan perdananya dan sebaliknya justru variabel kuadratiknya yang memiliki pengaruh positif terhadap nilai perusahaan perdananya. Hasil ini sesuai dengan penelitian Moussa (2013a, 2013b). Executives' slack dapat menurunkan nilai perusahaan perdana namun hanya sampai pada besaran tertentu namun setelah melewati besaran tersebut yang direpresentasikan dengan variabel executives' slack kuadratik maka nilai perusahaan perdananya justru menjadi semakin meningkat.

Penelitian ini memiliki beberapa implikasi penelitian antara lain bagi investor, penelitian ini membuktikan bahwa beberapa bentuk slack resources tertentu dapat menjadi landasan bagi investor dalam menilai perusahaan-perusahaan yang akan melakukan IPO. Bagi perusahaan, penelitian ini menunjukkan bahwa perusahaan harus terus memperhatikan slack resources yang optimal yang dapat meningkatkan nilai perusahaan di saat IPO. Sedangkan bagi peneliti, penelitian ini memperkaya literatur mengenai pengaruh tipe slack resources tertentu, dan kualitas pelaporan keuangan yang dapat mempengaruhi penilaian investor terhadap perusahaan yang melakukan IPO dengan menggunakan data yang tersedia di dalam prospektus IPO. 


\section{Tinjauan Teoritis}

\section{Signaling Theory}

Resource-based view (RBV) berasumsi bahwa resources dan kapabiliras terdistribusi secara heterogen ke seluruh perusahaan (Barney, 1991; Newbert, 2008). Perusahaan yang memiliki resources yang unik dapat menghasilkan economic rents jangka pendek dan jangka panjang serta mempertahankan keuntungan kompetitif dari resource tersebut sehingga perusahaan dapat membangun produk yang lebih baik untuk costs yang sama atau lebih rendah (Conner, 1991; Mahoney \& Pandian, 1992).

Slack resources pada mulanya disebut dengan istilah organizational slack sebagaimana pertama kali dikemukakan oleh Cyert dan March (1963). Cyert dan March (1963: 42) mendefinisikan organizational slack atau slack resources sebagai, "the difference between total resources and total necessary payments.” Bourgeois (1981) berpendapat bahwa slack resources dapat dipandang sebagai fasilitator dari strategic behavior. Keberadaan surplus resources membolehkan tindakan kreatif dan mendorong perusahaan untuk bersaing secara lebih agresif di dalam lingkungannya (Bourgeois, 1981). Perusahaan dapat lebih berkeinginan untuk berlanjut masuk ke dalam wilayah yang tidak dikenal, sehingga dapat menghadapi risiko yang lebih besar (Moses, 1992), dan bereksperimen dengan strategistrategi baru (Hambrick dan Snow, 1977; Thompson, 1967).

Penelitian IPO banyak yang menemukan bahwa sinyal tertentu (seperti underpricing) mempengaruhi kinerja IPO. Certo et al. (2001) menemukan struktur board dapat memberikan sinyal terkait kinerja IPO. Zimmerman (2008) dan Deeds et al. (1997) menemukan bahwa latar belakang fungsional, pendidikan serta certain scientific capabilities dapat mengirimkan sinyal yang kredibel mengenai kualitas bagi calon investor. Kinerja perusahaan umumnya diukur dengan menggunakan ukuran profitabilitas seperti return on assets (Greenley \& Oktemgil, 1998; Hambrick \& D'Aveni, 1988; Miller \& Leiblein, 1996; Wiseman \& Bromiley, 1996), return on equity (Greenley \& Oktemgil, 1998; Miller \& Leiblein, 1996; Wiseman \& Bromiley, 1996), return on investment (Greenley \& Oktemgil, 1998), atau return on sales revenue (Greenley \& Oktemgil, 1998; Wiseman \& Bromiley, 1996). Akan tetapi, Moussa (2009) berpandangan bahwa ukuran ini tidak berguna dalam kasus IPO firms dikarenakan kurangnya catatan public equity sales dan banyak di antaranya yang tidak memiliki laba maka dari itu digunakanlah IPO proceeds sebagai ukuran kinerja IPO.

Roy Sembel (1996) menjelaskan anomali IPO berdasarkan model WIPO (withdrawn IPO). Dari model ini, harga saham yang ditetapkan oleh underwriter mencerminkan 
keseluruhan nilai informasi yang ada dikarenakan underwriter perlu menjaga citranya di mata investor dan perusahaan yang akan melakukan IPO. Harga IPO mencerminkan harga wajar. Underwriter tidak akan melakukan overpricing ataupun underpricing IPO. IPO yang memiliki tipe excess resources atau slack resources tertentu dapat memberikan sinyal kepada calon investor berkenaan dengan prospek perusahaan di masa yang akan datang dan maka dari itu mengakumulasi lebih banyak capital (Moussa 2009) Oleh karena itu diharapkan akan berpengaruh positif. Berdasarkan pernyataan di atas, paper ini menggunakan ukuran value dari IPO firm yakni besaran pendanaan yang diperoleh atau timbul pada saat IPO atau proceeds-nya berdasarkan argumen bahwa underwriter menetapkan harga sesuai dengan informasi yang tercermin (Sembel, 1996). Dengan demikian, IPO Proceeds menjadi ukuran market valuation yang sesuai dalam konteks IPO untuk penelitian ini sesuai penelitian sebelumnya (Moussa 2009; Deeds et al., 1997; Finkle, 1998; Gulati \& Higgins, 2003; Zimmerman, 2008, DuCharme 2001; Hembel 1996).

Dalam penelitian ini, ukuran slack resources mengikuti ukuran dari Moussa (2009) yakni financial slack, innovational slack, dan managerial slack. Financial slack adalah bentuk slack yang paling sedikit terserap (the least absorbed), khususnya dikarenakan slack ini sepenuhnya dapat terbagi/dipisahkan untuk alokasi berbagai aktivitas (Greve, 2003), dapat disebut pula sebagai unabsorbed slack, yang menggunakan working capital dan cash reserves sebagai ukurannya sesuai dengan penelitian sebelumnya (Moussa, 2009; 2013) . Innovational slack merujuk pada resources yang tersedia untuk aktivitas riset dan pengembangan (Jellinek dan Schoonven 1990). Sedangkan managerial slack merupakan excess atau kelebihan manajer dan pengalaman manajerial relatif terhadap aset perusahaan dan merupakan salah satu cara untuk mengurangi tekanan high-growth serta mengurangi risiko kegagalan (Moussa 2009).

Penelitian-penelitian di Indonesia yang meneliti kualitas pelaporan keuangan mayoritas di antaranya menggunakan pengukuran kualitas pelaporan keuangan berbasis pasar. Kebanyakan mengujinya secara terpisah seperti menggunakan value relevance sebagaimana pernah diteliti oleh Rahmawati (2005); Susanto \& Ekawati (2006) dan menggunakan earnings response coefficent (Harahap, 2005; Naimah \& Sidharta, 2006 dalam Tryana 2011). Namun ada pula yang menggunakan atribut gabungan di dalam mengukur kualitas pelaporan keuangan seperti penelitian Pagalung (2006) yakni kualitas akrual, pererataan laba, persistensi, dan prediktabilitas. Penelitian ini menggunakan discretionary accrual dalam mengukur kualitas pelaporan keuangan yang terdapat di dalam prospektus IPO. Semakin 
tinggi indikasi manajemen laba melalui akrual diskresioner maka semakin rendah kualitas pelaporan keuangan yang dimiliki perusahaan IPO.

\section{Pengembangan Hipotesis}

Financial slack merujuk pada level aset yang tersedia bagi suatu organisasi (cash on hand) (Kraatz \& Zajac, 2001) yang dapat dengan mudah ditempatkan atau disalurkan oleh manajemen untuk berbagai kegunaan atau tujuan (Mishina et al., 2004). Financial slack dapat disebut juga sebagai unabsorbed slack..Financial slack dalam hal ini akan mengurangi capital restrictions dan meningkatkan pilihan strategis manajer untuk investasi, eksperimentasi, dan pengambilan risiko yang memiliki implikasi kinerja positif (George, 2005). Berdasarkan pernyataan ini, Penelitian ini mengajukan bahwa level financial slack yang tinggi memiliki pengaruh positif dengan valuasi perusahaan pada saat IPO sesuai dengan penelitian sebelumnya (Moussa 2009). Level financial slack yang semakin tinggi maka quality signalnya menjadi semakin kuat. Peneliti mengukur financial slack dengan 2 ukuran berbeda yakni cash reserves dan working capital mengikuti penelitian sebelumnya (Moussa 2009, 2013).

Cash reserves merepresentasikan cash on hand di suatu organisasi (Kraatz \& Zajac, 2001). Sedangkan working capital meng-captures aspek-aspek dari level current resources relatif terhadap aktivitas (Bourgeois \& Singh, 1983). Working capital mengukur net resources yang terikat di organisasi di dalam current atau operating assets relatif terhadap level aktivitas (Moses, 1992). Oleh karena itu, hipotesis yang diajukan adalah sebagai berikut

H1: Working capital slack memiliki pengaruh positif terhadap nilai perusahaan perdana

H2: Cash reserves slack memiliki pengaruh positif terhadap nilai perusahaan perdana

Inovasi dipandang beberapa penelitian sebelumnya sebagai sumber dari keuntungan kompetitif dibandingkan dengan perusahaan lainnya (Porter, 1990; Woodman, Sawyer, \& Griffin, 1993). Innovational slack memungkinkan eksperimen proyek dan strategi baru dengan lebih aman dan bebas di lingkungan yang lebih resource-constrained (Cyert \& March, 1992). Perusahaan yang memiliki level innovational slack yang tinggi yang langka, berharga, dan tidak dapat ditiru diasumsikan dapat mencapai keuntungan kompetitif sehingga investor akan memberikan value yang lebih tinggi terhadap perusahaan tersebut. Oleh karena itu, hipotesis yang diajukan adalah sebagai berikut:

H3: $\quad R \& D$ slack memiliki pengaruh positif terhadap nilai perusahaan perdana 
Semakin besar $R \& D$ spending juga tidak baik. Liebenstein (1969) yang menyatakan bahwa slack mengurangi insentif untuk berinovasi dan mendorong investasi R\&D yang belum tentu menghasilkan keuntungan ekonomis. Nohria dan Gulati (1969) berpendapat bahwa pengaruh sebenarnya antara slack dan inovasi adalah bersifat kurvilinear. Innovational slack berupa pengeluaran $R \& D$ akan membawa hasil yang positif sampai pada titik tertentu namun setelah melewati titik tersebut innovational slack akan menghasilkan ketidakefisiensian di masa yang akan datang dan membawa hasil yang negatif. Oleh karena itu hipotesis yang diajukan adalah sebagai berikut:

H4: $\quad R \& D$ slack memiliki pengaruh non-linear negatif (U-Terbalik) terhadap nilai perusahaan perdana.

Managerial slack didefinisikan sebagai 'specialized and skilled top management team resources that are rare and absorbed' (Mishina et al. 2004). Peran managerial slack telah menjadi pembahasan dari penelitian Penrose (1959) yang mengemukakan betapa pentingnya tipe slack resources ini dalam pertumbuhan perusahaan. Managerial slack sangat berkaitan erat dengan isolating mechanisms di antaranya adalah firm-specific knowledge, dan managers' shared, team-specific experience (Kor dan Mahoney 2004). Pengalaman dan pengetahuan ini yang memberikan mereka kesempatan produktif yang unik bagi perusahaan (Moussa 2009). Dengan demikian, hipotesis yang diajukan adalah sebagai berikut:

H5: Executives slack memiliki pengaruh positif terhadap nilai perusahaan perdana.

Semakin sedikit jumlah manajemen yang ada di perusahaan tersebut maka perusahaan tersebut dianggap tidak memiliki kepengurusan yang baik dan perusahaan dianggap tidak berkomitmen dalam mempersiapkan diri selama proses IPO sedangkan apabila jumlah manajemen terlalu banyak maka perusahaan dipandang tidak efisien dan melakukan pemborosan dengan mempekerjakan manajemen dengan jumlah yang banyak (Moussa 2013). Oleh karena itu hipotesis yang dikembangkan adalah sebagai berikut:

H6: Executives slack memiliki pengaruh non-linear negatif (U-terbalik) terhadap nilai perusahaan perdana

Moussa (2009) menyatakan bahwa pengalaman dapat menjadi sinyal dari kualitas. Menurut RBV, untuk mencapai keuntungan kompetitif dan return yang lebih besar, perusahaan selain harus memiliki resources yang unik juga harus bisa mengelola resources 
tersebut (Mahoney, 1995). Oleh karena itu, manajer dengan pengalaman industry-specific mangement akan memiliki pengaruh positif terhadap kinerja dan survival perusahaan (Moussa 2009). Dengan demikian hipotesis yang diajukan adalah sebagai berikut:

H7: Executives' experience slack memiliki pengaruh positif terhadap nilai perusahaan perdana.

Financial slack yang ada di dalam laporan keuangan sangat bergantung pada kualitas pelaporan keuangan dan discretionary accruals memberikan sinyal atas kualitas informasi pada perusahaan IPO sehingga dapat mempengaruhi hubungan financial slack terhadap nilai perusahaan perdana. Semakin tinggi discretionary current accruals maka semakin tinggi indikasi manajemen memanipulasi angka-angka di dalam laporan keuangan termasuk di dalamnya adalah informasi financial slack. Sun et al. (2012) menggunakan kualitas akrual sebagai variabel yang mempengaruhi hubungan antara financial slack dengan nilai perusahaannya. Mereka meneliti value dari cash holdings dan menemukan bahwa discretionary accruals memperlemah value dari cash holdings perusahaan. Excess cash (cash reserves slack) yang dimiliki perusahaan dianggap memiliki agency problems dan hal tersebut diperburuk dengan kualitas laba yang buruk. Investor terbukti mendiskonto value dari cash holdings terutama dengan adanya kualitas laba yang buruk karena kekhawatiran adanya penyalahgunaan excess cash tersebut untuk kepentingan pribadi manajemen, apalagi cash merupakan aset yang paling mudah dialihkan (Myers \& Rajan 1998; Lie 2000). Oleh karena itu, hipotesis yang diajukan adalah sebagai berikut:

H8: discretionary current accruals memberikan pengaruh negatif terhadap hubungan antara working capital slack dengan nilai perusahaan perdana.

H9: discretionary current accruals memberikan pengaruh negatif terhadap hubungan antara cash reserves slack dengan nilai perusahaan perdana.

\section{Metode Penelitian}

\section{Populasi, Sampel dan Data}

Populasi yang digunakan dalam penelitian ini adalah perusahaan yang melakukan penawaran umum perdana (IPO) di Bursa Efek Indonesia (BEI) yang berada pada industri tertentu yang banyak memiliki beban riset dan pengembangan yaitu agriculture, consumer goods, basic industry \& chemicals dan trade, services \& investment sesuai dengan Jakarta Stock Exchange Classification Index (JASICA Index). Jenis data yang digunakan adalah data 
sekunder yakni prospektus IPO. Prospektus IPO setiap perusahaan digunakan karena memberikan informasi yang diperlukan dan dapat mengungkapkan informasi berharga bagi investment bankers, regulator, investor, dan pihak terkait lainnya (Beatty \& Zajac, 1994).

\section{Metode Pengambilan Sampel}

Metode sampling yang digunakan dalam penelitian ini adalah non probability sampling dengan teknik pengambilan sampel purposive sampling, yaitu teknik pengambilan sampel dengan mendasarkan pada ciri-ciri atau kriteria tertentu. Kriteria sampel yang digunakan sebagai berikut:

a. Perusahaan yang menjadi sampel adalah perusahaan yang melakukan penawaran saham perdana yang berada pada sektor industri tertentu yakni basic industry \& chemicals, agriculture, consumer goods,others serta trade, services \& investment yang banyak memiliki data riset dan pengembangan.

b. Sampel perusahaan yang melakukan IPO merupakan sampel perusahaan yang ada di industri tertentu tersebut yang memiliki data lengkap pada prospektus IPO untuk variabel-variabel yang akan diteliti (financial slack, innovational slack, managerial slack, serta discretionary current accruals)

c. Prospektus IPO perusahaan sampel didapatkan dari berbagai sumber antara lain perpustakaan Bursa Efek Indonesia, website resmi perusahaan yang mempublikasikan prospektus perdana, website resmi Bursa Efek Indonesia juga dari website internet lainnya.

d. Laporan keuangan perusahaan benchmark untuk menghitung variabel discretionary current accruals diperoleh dari Indonesian Capital Market Directory dan Indonesian Capital Market Electronic Library.

e. Data reputasi underwriter diperoleh dari IDX Factbook. IDX Factbook hanya tersedia untuk tahun 1992-2014 yang diperoleh dari Indonesian Capital Market Electronic Library di Bursa Efek Indonesia.

f. Perusahaan IPO yang menjadi sampel setidaknya memiliki 4 perusahaan non-IPO di sektor yang sama yang menjadi benchmark dalam menghitung discretionary current accruals. 


\section{Model Penelitian}

Metode analisis yang digunakan untuk menguji hipotesis dalam penelitian ini adalah analisis regresi linier berganda dengan menggunakan persamaan moderated regression analysis untuk menguji analisis regresi yang menggunakan unsur interaksi (Ghozali, 2008) seperti moderasi. Berikut persamaan regresinya:

$$
\begin{aligned}
V_{i}= & \alpha+\beta_{1} W C_{i t}+\beta_{2} C R_{i t}+\beta_{3} R D_{i t}+\beta_{4} R^{2}{ }_{i t}+\beta_{5} E X E C_{i}+\beta_{6} E X E C_{i}^{2}+\beta_{7} E X P E R_{i}+\beta 8 \\
& N E G D C A_{i t}+\beta 9 W C_{i t} * N E G D C A_{i t}+\beta_{10} C R_{i t}{ }^{*} N E G D C A_{i t}+\beta_{11} A G E_{i}+\beta_{12} R I S K_{i}+ \\
& \beta_{13}{ }_{13} D_{i}+\varepsilon
\end{aligned}
$$

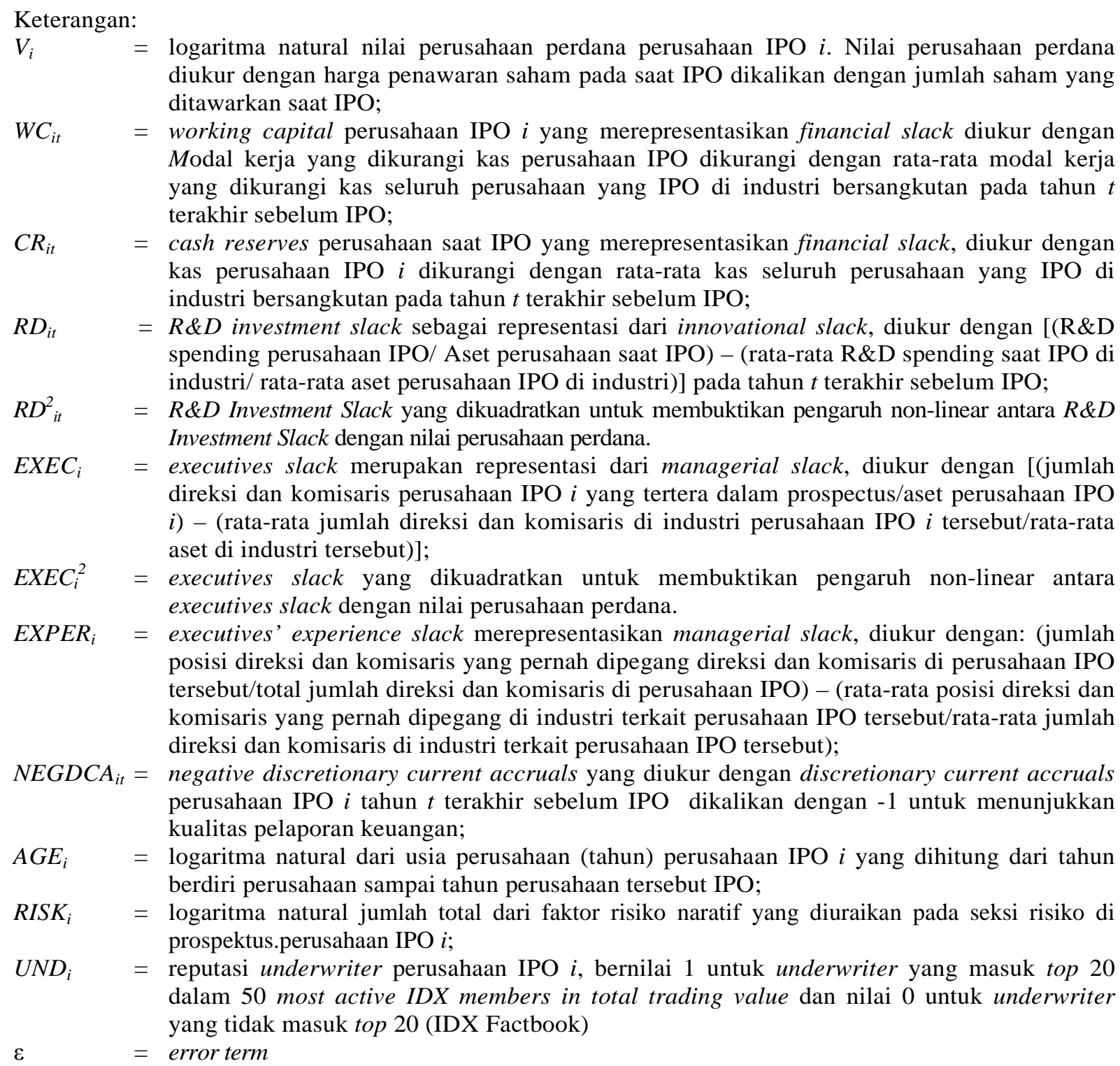

Pengukuran discretionary accruals dalam konteks IPO menggunakan pengukuran dari Tykova (2006) yang lebih sesuai digunakan karena hanya memiliki tiga (3) periode laporan keuangan. Berikut pengukurannya: Nilai NDCA perusahaan yang melakukan IPO (perusahaan i) diestimasi menggunakan komponen-komponen NDCA dari perusahaan lain (perusahaan $k$ ) 
yang berada dalam sektor industri yang sama dengan perusahaan IPO (sektor $j$ ) di tahun yang sama dengan tahun perusahaan IPO $t$ terakhir menjelang IPO (tahun $t$ ). NDCA dari perusahaan dalam sektor $j$ (sektor yang sama tersebut) diregresi dan hasil estimasinya digunakan sebagai koefisien regresi untuk menghitung komponen NDCA dari perusahaan IPO. Berikut tahapannya:

a. $\quad$ Current Accruals (CA) perusahaan IPO pada tahun $t$ dihitung dengan:

$C A=\Delta$ (Aset Lancar - Kas) $-\Delta($ Kewajiban Lancar - Kewajiban Jangka Panjang yang Jatuh Tempo dalam Waktu 1 Tahun)

b. Komponen NDCA perusahaan-perusahaan $k$ yang berada dalam sektor $j$ (sektor yang sama) dengan perusahaan IPO pada tahun $t$ terakhir menjelang IPO $(t)$, dihitung dengan:

$\frac{C A_{j k, t}}{T A_{j k, t-1}}=\alpha_{j, t, 0} \frac{1}{T A_{j k, t-1}}+\alpha_{j, t, 1} \frac{\Delta R E V_{j k, t}}{T A_{j k, t-1}}+\varepsilon_{j k, t}$

Keterangan:

$C A_{j, k, t}=$ Current accruals perusahaan-perusahaan $k$ yang berada dalam sektor $j$ pada tahun $t$ terakhir menjelang IPO

$T A_{j, k, t-1}=$ Aset total perusahaan-perusahaan $k$ yang berada dalam sektor $j$ satu tahun sebelum tahun $t$ terakhir menjelang IPO ( $t-1)$

$\triangle R E V_{j, k, t}=$ Selisih pendapatan perusahaan-perusahaan $k$ yang berada dalam sektor $j$ pada tahun $t$ dibanding pendapatan pada tahun $t-1$

$\alpha_{j, t, 0} ; \alpha_{j, t, 1}=$ Koefisien regresi dari komponen NDCA perusahaan-perusahaan $k$ yang berada dalam sektor $j$

c. $\quad$ NDCA perusahaan IPO pada tahun $t$ terakhir menjelang IPO $(t)$ dengan menggunakan koefisien regresi dari komponen NDCA perusahaan-perusahaan $k$ yang berada dalam sektor $j$, dihitung dengan persamaan:

$N D C A_{j i, t}=\alpha_{j, t, 0} \frac{1}{T A_{j i, t-1}}+\alpha_{j, t, 1} \frac{\Delta R E V_{j i, t}-\Delta T R_{j i, t}}{T A_{j i, t-1}}$

Keterangan:

$N D C A_{j i, t}=$ Nilai non discretionary current accruals (NDCA) perusahaan IPO yang berada dalam sektor $j$ pada tahun $t$ terakhir menjelang IPO $(t)$

$T A_{j i, t-1}=$ Aset total perusahaan IPO yang berada dalam sektor $j$ satu tahun sebelumn tahun $t$ terakhir menjelang IPO $(t-1)$

$\triangle R E V_{j, i, t}=$ Selisih pendapatan perusahaan IPO yang berada dalam sektor $j$ pada tahun $t$ dibanding pendapatan pada tahun $t-1$

$\Delta T R_{j i, t} \quad=$ Selisih piutang usaha perusahaan IPO yang berada dalam sektor $j$ pada tahun $t$ dibanding piutang usaha pada tahun $t-1$

$\alpha_{j, t, 0} ; \alpha_{j, t, 1}=$ Koefisien regresi dari komponen NDCA perusahaan-perusahaan $k$ yang berada dalam sektor $j$ dari persamaan sebelumnya:

d. Kemudian, DCA perusahaan IPO pada tahun $t$ dalam sektor $j$, dihitung dengan: 
$D C A_{j i, t}=\frac{C A_{j i, t}}{T A_{j i, t-1}}-N D C A_{j i, t}$

Keterangan:

$D C A_{j, i, t}=$ Discretionary current accruals perusahaan IPO yang berada dalam sektor $j$ pada tahun $t$ terakhir menjelang IPO $(t)$

$C A_{j, i, t}=$ Current accruals perusahaan IPO yang berada dalam sektor $j$ pada tahun $t$ terakhir menjelang IPO $(t)$

\section{Hasil Penelitian}

\section{Hasil Pemilihan Sampel}

Berikut hasil pemilihan sampel berdasarkan kriteria sampel yang telah disebutkan sebelumnya:

\section{Tabel 1 Hasil Pemilihan Sampel}

\begin{tabular}{|l|c|c|c|}
\hline \multicolumn{1}{|c|}{ Sektor Industri } & $\begin{array}{c}\text { Jumlah perusahaan } \\
\text { IPO }\end{array}$ & $\begin{array}{c}\text { Jumlah Perusahaan IPO } \\
\text { yang tidak memiliki data } \\
\text { lengkap slack di dalam } \\
\text { prospektus }\end{array}$ & $\begin{array}{c}\text { Jumlah Sampel yang memiliki } \\
\text { data lengkap slack resources di } \\
\text { dalam prospektus }\end{array}$ \\
\hline Agriculture & 22 & $(14)$ & 86 \\
\hline $\begin{array}{l}\text { Basic Industry \& } \\
\text { Chemicals }\end{array}$ & 65 & $(19)$ & 32 \\
\hline Others & 44 & $(12)$ & 26 \\
\hline Consumer Goods & 39 & $(11)$ & 6 \\
\hline $\begin{array}{l}\text { Trade, Services \& } \\
\text { Investment }\end{array}$ & 119 & 118 \\
\hline \multicolumn{2}{|c|}{ Jumlah Perusahaan IPO yang memiliki data lengkap slack resources } \\
\hline \multicolumn{2}{|c|}{ Perusahaan sampel yang tidak memiliki data reputasi underwriter } \\
(perusahaan yang IPO di bawah tahun 1992)
\end{tabular}

\section{Statistik Deskriptif dan Matriks Korelasi}

Berikut tabel statistik deskriptif dan matriks korelas masing-masing variabel yang digunakan dalam penelitian ini dari 62 sampel yang akan diuji

Tabel 2 Statistik Deskriptif

\begin{tabular}{|c|c|c|c|c|c|}
\hline Variabel & Mean & Median & Maksimum & Minimum & Std. Deviasi \\
\hline $\begin{array}{c}V(\text { dalam } \\
\text { milyaran } \\
\text { rupiah) }\end{array}$ & 227.47 & 82.50 & 1344 & 12 & 325.14 \\
\hline$W C$ & -0.02 & -0.03 & 1.02 & -0.39 & 0.20 \\
\hline$C R$ & -0.02 & -0.03 & 0.33 & -0.17 & 0.12 \\
\hline$R D$ & 0.01 & -0.003 & 0.38 & -0.05 & 0.05 \\
\hline$E X E C$ & $5.30 \mathrm{E}-11$ & $1.61 \mathrm{E}-11$ & $7.69 \mathrm{E}-10$ & $-4.52 \mathrm{E}-11$ & $1.25 \mathrm{E}-10$ \\
\hline
\end{tabular}


Tabel 2 Statistik Deskriptif (lanjutan)

\begin{tabular}{|c|c|c|c|c|c|}
\hline Variabel & Mean & Median & Maksimum & Minimum & Std. Deviasi \\
\hline$E X P E R$ & -0.09 & -0.43 & 7.99 & -3.88 & 2.21 \\
\hline$D C A$ & 0.16 & -0.01 & 8.96 & -0.70 & 1.22 \\
\hline$A G E$ & 18.55 & 16.00 & 90.00 & 3.00 & 13.55 \\
\hline$R I S K$ & 11.66 & 8.00 & 51.00 & 4.00 & 9.22 \\
\hline$U N D$ & 0.52 & 1.00 & 1.00 & 0.00 & 0.50 \\
\hline
\end{tabular}

Tabel 3 Matriks Korelasi

\begin{tabular}{|c|c|c|c|c|c|c|c|c|c|}
\hline & $W C$ & $C R$ & $R D$ & EXEC & EXPER & DCA & AGE & RISK & UND \\
\hline$W C$ & 1.00 & & & & & & & & \\
\hline$C R$ & 0.16 & 1.00 & & & & & & & \\
\hline$R D$ & -0.20 & 0.21 & 1.00 & & & & & & \\
\hline$E X E C$ & -0.07 & 0.26 & 0.13 & 1.00 & & & & & \\
\hline$E X P E R$ & 0.15 & -0.02 & 0.11 & -0.08 & 1.00 & & & & \\
\hline NEGDCA & -0.19 & 0.11 & 0.04 & 0.08 & 0.07 & 1.00 & & & \\
\hline$A G E$ & 0.29 & -0.06 & -0.16 & -0.12 & 0.05 & -0.00 & 1.00 & & \\
\hline$R I S K$ & 0.14 & 0.26 & 0.03 & -0.14 & 0.22 & -0.07 & 0.27 & 1.00 & \\
\hline$U N D$ & 0.04 & 0.04 & -0.15 & -0.04 & -0.11 & -0.17 & 0.06 & -0.16 & 1.00 \\
\hline
\end{tabular}

Dapat dilihat dari hasil analisis statistik deskriptif bahwa, nilai perusahaan perdana atau proceeds bervariasi dari nilai minimum Rp. 12 miliar sampai maksimum Rp. 1344 miliar. Sedangkan financial slack (WC, $C R$ ) rata-rata lebih rendah dibandingkan rata-rata perusahaan IPO yang ada di industri yang sama (-0.02). Hasil ini berarti sebagian besar kas dan modal kerja perusahaan IPO rendah dibandingkan jumlah yang diperlukan pada sektor industrinya. Kas dan modal kerja yang rendah ini dapat dikaitkan dengan alasan utama perusahaan melakukan IPO adalah memperoleh dana segar berupa kas untuk membiayai modal kerja, hutang dan proyek-proyek investasi yang diperlukan. Exectives' slack memiliki rata-rata lebih tinggi dibandingkan rata-rata jumlah eksekutif di industri yang sama. Rata-rata perusahaan yang melakukan IPO memiliki direksi dan komisaris lebih banyak dari biasanya. Sebagian besar perusahaan ingin mempersiapkan tenaga manajemen yang lebih dari biasanya agar IPO dapat berjalan dengan baik. Executives'experience slack juga memiliki nilai yang bervariasi.

Rata-rata perusahaan yang melakukan IPO memiliki $R \& D$ slack sedikit lebih tinggi. Perusahaan yang akan melakukan IPO akan menunjukkan kemampuannya dalam berinovasi dan mengeluarkan produk-produk baru untuk terus berkembang dan dapat bersaing di antara pesaing-pesaingnya. Sedangkan hasil statistik deskriptif akrual diskresioner jangka pendek yang menunjukkan kualitas pelaporan keuangan yang rendah membuktikan bahwa sebagian besar perusahaan IPO memanipulasi akrual untuk meningkatkan laba yang tidak mencerminkan keadaan yang sebenarnya. 


\section{Pembahasan}

Di bawah ini ditunjukkan hasil pengujian signifikansi antara masing-masing variabel financial slack $(C R, W C)$, innovational slack $(R D)$, dan managerial slack (EXEC, EXPER), dalam menjelaskan nilai perusahaan perdana dengan discretionary current accruals (DCA) sebagai variabel moderasi.

\section{Tabel 4 Hasil Regresi Model}

\begin{tabular}{|c|c|c|c|c|}
\hline \multicolumn{5}{|c|}{$\begin{array}{c}V_{i}=\alpha+\beta 1 W C_{i t}+\beta_{2} C R_{i t}+\beta_{3} R D_{i t}+\beta_{4} R D_{i t}^{2}+\beta_{5} E X E C_{i}+\beta_{6} E X E C_{i}^{2}+\beta_{7} E X P E R_{i}+\beta_{8} N E G D C A_{i t}+ \\
\beta_{9} W C_{i t}{ }^{*} N E G D C A_{i t}+\beta_{10} C R_{i t}^{*} N E G D C A_{i t}+\beta_{11} A G E_{i}+\beta_{12} R I S K_{i}+\beta_{13} U N D_{i}+\varepsilon\end{array}$} \\
\hline Variabel & $\begin{array}{l}\text { Ekspektasi } \\
\text { Tanda }\end{array}$ & Koefisien & t-statistic & $\begin{array}{c}p \text {-value } \\
\text { (one-tailed) }\end{array}$ \\
\hline$W C$ & + & 0.387085 & 0.547517 & 0.29 \\
\hline$C R$ & + & 1.830895 & 1.509864 & $0.07 *$ \\
\hline$R D$ & + & 14.86987 & 2.248612 & $0.01 * * *$ \\
\hline$R D^{2}$ & - & -37.76643 & -1.966939 & $0.03 * *$ \\
\hline EXEC & + & $-9.27 \mathrm{E}+09$ & -3.103717 & $0.00 * * *$ \\
\hline$E X E C^{2}$ & - & $1.50 \mathrm{E}+19$ & 3.074663 & $0.00 * * *$ \\
\hline EXPER & + & -0.070966 & -1.306276 & $0.10 *$ \\
\hline NEGDCA & - & -0.653959 & -1.937476 & $0.03 * *$ \\
\hline WC*NEGDCA & - & -0.244188 & 0.095456 & 0.46 \\
\hline$C R^{*} N E G D C A$ & - & -18.40854 & -3.079111 & $0.00 * * *$ \\
\hline$A G E$ & + & 0.487377 & 2.577209 & $0.01^{* * *}$ \\
\hline RISK & - & 1.040149 & 4.461607 & $0.00 * * *$ \\
\hline$U N D$ & + & 0.210486 & 0.846370 & 0.20 \\
\hline
\end{tabular}

\section{Pengujian Hipotesis 1: Pengaruh Working Capital Slack terhadap Nilai Perusahaan Perdana}

Hasil regresi menunjukkan variabel working capital slack (WC) tidak memiliki pengaruh terhadap nilai perusahaan perdananya. Hasil ini membuktikan bahwa investor belum memandang working capital slack sebagai kualitas suatu perusahaan. Working capital memiliki risiko likuiditas karena merupakan resource yang berisiko tidak mudah diuangkan yang dapat digunakan untuk operasionasionalisasi perusahaan. Sehingga perusahaan memerlukan cash atau fund yang cukup apabila terjadi kesulitan dalam memenuhi kebutuhan modal kerjanya (Moussa 2013). Working capital slack juga dapat dipengaruhi oleh variabel lain yakni $R \& D$ Slack. Korelasi negatif antara working capital slack dengan $R \& D$ slack sebesar 20\% yang menunjukkan semakin tinggi working capital slack maka semakin rendah $R \& D$ slack yang dimilikinya (lihat Tabel 3). Working capital slack digunakan perusahaan untuk melakukan investasi yang lebih dapat menguntungkan perusahaan seperti melakukan investasi $R \& D$ dibandingkan harus menyimpan working capital slack yang dapat menimbulkan inefisiensi dan memiliki risiko likuiditas (Aktas et al. 2014). 


\section{Pengujian Hipotesis 2: Pengaruh Cash Reserves Slack terhadap Nilai Perusahaan Perdana}

Dari hasil regresi, financial slack berupa kas (CR) yang lebih besar dibandingkan dengan rata-rata sector industri memiliki pengaruh positif terhadap nilai perusahaan perdana atau IPO proceeds-nya. Fleksibilitas yang diberikan oleh financial slack, dalam hal ini cash reserves slack, menjadi penting agar IPO dapat berjalan dengan baik. Cash reserves slack dapat memberikan fleksibilitas yang diperlukan selama periode ketidakpastian dengan memberikan manajemen resources untuk mengambil keuntungan/manfaat dari kesempatan yang muncul dan menyelesaikan demands for growth yang tidak dapat diantisipasi (Moussa 2009). Cash reserves slack akan mengurangi capital restrictions dan meningkatkan pilihan strategis manajer untuk investasi, eksperimentasi, dan pengambilan risiko yang memiliki implikasi kinerja positif (George, 2005). Investor menilai tinggi excess cash atau cash reserves slack yang dimiliki perusahaan karena excess cash dapat meningkatkan dividen. Cash reserves slack ini diperhatikan investor karena merupakan cara yang mudah untuk mendapatkan returns yang besar tanpa harus melihat tingkat pertumbuhan perusahaan.

\section{Pengujian Hipotesis 3: Pengaruh $R \& D$ Slack terhadap Nilai Perusahaan Perdana}

Variabel $R \& D$ Slack, slack resources berupa jumlah $R \& D$ spending yang lebih besar di atas rata-rata sektor industri, terbukti memiliki pengaruh positif terhadap nilai perusahaan perdananya. Hasil ini berarti bahwa investor menghargai adanya riset dan pengembangan sebagai sinyal bahwa perusahaan tersebut berinovasi agar perusahaan terus berkembang dan memiliki keuntungan kompetitif (Moussa 2009, 2013). Bagi perusahaan yang sudah memiliki inovasi yang sudah terbukti seperti perusahaan di sektor industri farmasi, innovational slack dinilai secara positif oleh investor karena investasi $R \& D$ tersebut memberikan peran penting pada pertumbuhan dan kelangsungan hidup perusahaan. Innovational slack menunjukkan bahwa perusahaan telah melakukan banyak pertimbangan atas investasi $R \& D$ yang dilakukan terhadap expected returns yang akan diperoleh. Innovational slack membutuhkan dana yang besar dan manajemen tidak akan mengambil risiko yang tidak akan menguntungkan perusahaan kecuali memiliki value bagi perusahaan di masa yang akan datang.

\section{Pengujian Hipotesis 4: Pengaruh Non-Linear (U-terbalik) $R \& D$ Slack terhadap Nilai Perusahaan Perdana}

Sedangkan variabel kuadratiknya $\left(R D^{2}\right)$ memiliki pengaruh negatif terhadap nilai perusahaan perdananya. Hubungan negatif bisa disebabkan karena kurang tepatnya alokasi 
resource. Terdapat risiko di mana proyek yang sia-sia masih terus dilanjutkan (proyek yang memiliki risiko tinggi dan net present value-nya negatif) dan risiko proyek yang seharusnya berhasil namun kurang adanya dana membuat proyek tersebut dihentikan (Nohria \& Gulati 1996). $R \& D$ slack yang sangat besar memberikan pengaruh negatif terutama bagi perusahaan-perusahaan muda yang belum memiliki inovasi-inovasi yang terbukti serta yang produktivitas $R \& D$-nya kecil, Besaran investasi $R \& D$ yang tidak diimbangi dengan sumber daya teknis serta fasilitas yang memadai dianggap investor akan memperburuk kinerja perusahaan di masa yang akan datang.

\section{Pengujian Hipotesis 5: Pengaruh Executive Slack terhadap Nilai Perusahaan Perdana}

Executive slack justru memiliki pengaruh negatif terhadap nilai perusahaan perdananya. Executives slack yang tidak terlalu besar sebagai tidak efisien dan memberikan sinyal kurangnya komitmen serta tidak cukup untuk mengambil inisiatif-inisiatif besar seperti mengakuisisi perusahaan lain (Brau \& Fawcett 2006). Zimmerman (2006) menyatakan bahwa umumnya perusahaan-perusahaan yang baru akan memulai IPO, baru menambah jumlah manajemennya sesaat sebelum IPO, dengan harapan meningkatkan perolehan dana hasil IPO dan untuk mengurangi kekhawatiran investor. Executives slack yang diuji pada penelitian ini sebagian besar terbukti berada pada besaran moderate level (variabel non-kuadratiknya). Executives' slack yang memadai tanpa diikuti dengan kompetensi dan kapabilitas yang memadai akan memberikan sinyal negatif bagi investor. Market akan melihat faktor-faktor lain selain jumlah direksi dan komisaris yakni reputasi executives dan prestasi executives tersebut di masa lalu. Berikut grafik scatterplot hubungan executives' slack terhadap nilai perusahaan perdana.

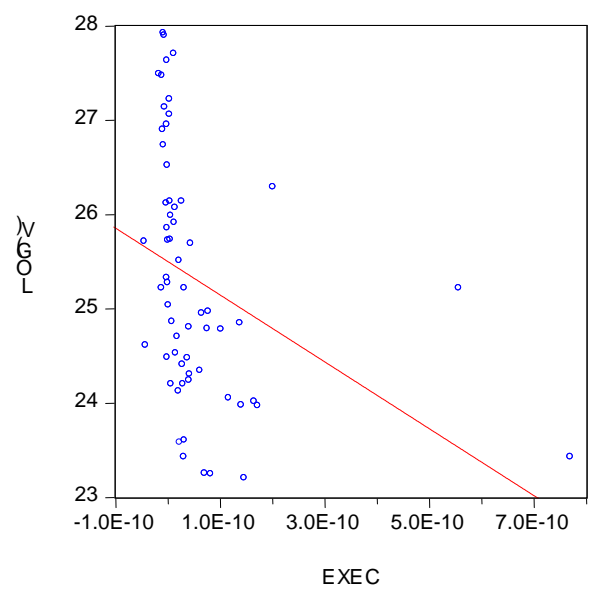




\section{Pengujian Hipotesis 6: Pengaruh Non-Linear (U-terbalik) Executives Slack terhadap Nilai Perusahaan Perdana}

Hasil regresi menunjukkan bahwa, executive slack justru tidak memiliki pengaruh non-linear (U-terbalik) namun justru kebalikannya. Hal ini berbeda dengan ekspektasi. Pada besaran kuadratiknya (EXEC $\left.{ }^{2}\right)$, executives' slack akan lebih disukai investor dan meningkatkan proceeds-nya (signifikan pada $\alpha<1 \%$ ). Hasil ini juga selaras dengan hasil penelitian Moussa (2013), yang didukung dengan argumen Penrose (1959). Mereka menyatakan bahwa, executive slack yang tinggi menandakan adanya komitmen manajemen perusahaan dalam mengakumulasi resources yang diperlukan agar perusahaan berkembang (Moussa 2013).

Executives' slack kuadratik juga dapat dipengaruhi oleh corporate governance dari perusahaan IPO tersebut. Adanya komisaris independen serta banyaknya saham yang dimiliki oleh manajemen juga bisa mempengaruhi penilaian investor terhadap perusahaan IPO tersebut. Banyaknya jumlah manajemen memperkuat pengawasan antar direksi dan komisaris dan memperkecil peluang konflik antara prinsipal dan agen. Perusahaan yang menempatkan executives' slack kuadratik merupakan agency costs yang timbul dari kondisi informasi asimetri yang besar seperti IPO. Executives' slack kuadratik memperkecil peluang moral hazard yang dilakukan oleh manajemen yang mengambil keuntungan dari posisi yang dipegang untuk kepentingan dirinya sendiri dengan mengorbankan value perusahaan.

\section{Pengujian Hipotesis 7: Pengaruh Experience Slack terhadap Nilai Perusahaan Perdana}

Variabel experience slack berupa jumlah posisi direksi dan komisaris yang dipegang di posisi terkait yang dibandingkan dengan rata-rata sektor industrinya memiliki pengaruh negatif terhadap nilai perusahaan perdananya. Hasil ini dapat disebabkan oleh adanya larangan atas posisi rangkap direksi dan komisaris yang dapat mengakibatkan terjadinya persaingan usaha tidak sehat. Dalam UU No.5 Tahun 1999 (UU Anti Monopoli), rangkap jabatan pada sektor industri yang sama menimbulkan litigation risk yang berpotensi menimbulkan sanksi pidana (pelanggaran Pasal 26). Litigation risk hypothesis menjelaskan bahwa perusahaan yang memiliki litigation risk tinggi justru menurunkan offer price sebagai insurance atas risiko litigasi yang akan dihadapi dan sebagai akibatnya memiliki nilai perdana yang rendah (Ljungqvist, 2005; Ibbotson 1975). Nilai perdana yang rendah ini membuat nilai underpricing menjadi tinggi. Initial return yang besar dari underpricing inilah yang memberikan insurance atas litigation risk yang dimiliki perusahaan. 


\section{Pengujian Hipotesis 8: Pengaruh Negative Discretionary Current Accruals terhadap Hubungan antara Working Capital Slack dengan Nilai Perusahaan Perdana}

Dari hasil pengujian interaksi variabel working capital slack dengan discretionary current accruals negatif (NEGDCA) yang menunjukkan kualitas pelaporan keuangan terbukti bahwa discretionary current accruals tidak memberikan pengaruh terhadap hubungan antara working capital slack terhadap nilai perusahaan perdananya. Hal ini dikarenakan working capital slack berkorelasi negatif dengan $R \& D$ slack. Working capital slack juga terikat pada operasionalisasi perusahaan sehari-hari dan kualitas pelaporan keuangan seperti akrual tidak mempengaruhi hubungan ini. Investor cenderung melihat bagaimana working capital digunakan untuk pertumbuhan perusahaan, salah satunya adalah dengan melakukan investasi $R \& D$ (Aktas et al., 2014). Working capital slack juga memiliki unsur inventory dan receivables yang besar dan sangat bergantung pada seberapa cepat inventory dan receivables tersebut diuangkan. Excess inventory dan receivables ini tidak bisa dengan mudah dimanipulasi karena sifatnya yang tidak lebih liquid dibandingkan dengan cash reserves slack. Manajemen tidak bisa dengan mudah mengalihkan working capital slack untuk kepentingan pribadinya tanpa diuangkan terlebih dahulu.

\section{Pengujian Hipotesis 9: Pengaruh Discretionary Current Accruals terhadap Hubungan antara Cash Reserves Slack dengan Nilai Perusahaan Perdana}

Discretionary current accruals terbukti memberikan pengaruh negatif terhadap hubungan antara cash reserves slack dengan nilai perusahaan perdana. Hal ini dapat dilihat dengan koefisien variabel interaksi antara cash reserves slack dengan discretionary current accruals yang memberikan pengaruh negatif terhadap nilai perusahaan perdana (signifikan pada $\alpha=1 \%$ ). Cash reserves slack pada laporan keuangan berkualitas buruk dianggap memperparah agency problems karena manajemen dapat dengan mudah mengalihkan excess cash tersebut untuk kepentingan pribadinya. Hasil ini mendukung penelitian Sun et al. (2012) yang menunjukkan bahwa excess cash dari kualitas pelaporan keuangan yang buruk menurunkan nilai perusahaan di mata investor dan hal tersebut tercermin dari harga saham yang rendah. Mereka menemukan bahwa investor mendiskonto value dari cash holdings dengan adanya kualitas laba yang buruk karena kekhawatiran adanya penyalahgunaan excess cash tersebut untuk kepentingan pribadi manajemen, apalagi cash merupakan aset yang paling mudah dialihkan (Myers \& Rajan 1998; Lie 2000). 


\section{Kesimpulan}

Penelitian ini menganalisis pengaruh slack resources (financial slack, innovational slack, dan managerial slack) terhadap nilai perusahaan perdana dengan kualitas pelaporan keuangan, sebagai variabel moderasi pada perusahaan dalam konteks yang unik yaitu pada saat IPO. Penelitian ini melakukan pengujian terhadap 62 perusahaan sampel, diuji dari 4 sektor industri (basic industry \& chemicals, agriculture, others, dan retail, trade \& investment).

Hasil peneilitian menunjukkan working capital slack ternyata tidak memiliki pengaruh terhadap nilai perusahaan perdana. Sedangkan, cash reserves slack memiliki pengaruh positif terhadap nilai perusahaan perdana. Cash reserves slack dianggap dapat memberikan fleksibilitas yang diperlukan selama periode ketidakpastian dengan memberikan manajemen resources untuk mengambil keuntungan/manfaat dari kesempatan yang ada dan menyelesaikan demands for growth yang tidak dapat diantisipasi (Moussa 2009, George 2005).

Innovational Slack $(R D)$ terbukti memiliki pengaruh positif terhadap nilai perusahaan perdananya. Selain itu, Innovational Slack kuadratik terbukti memberikan pengaruh nonlinear (U-terbalik) negatif terhadap nilai perusahaan perdana. $R \& D$ Slack yang melebihi batas optimum dapat memberikan sinyal bahwa perusahaan IPO melakukan pemborosan dan inefisiensi. Hasil penelitian juga menunjukkan bahwa investor justru lebih menghargai adanya executives slack kuadratik $\left(E X E C^{2}\right)$ di atas rata-rata sektor industrinya dibandingkan jumlah executives slack (EXEC). Executives slack kuadratik menandakan adanya komitmen perusahaan untuk mengakumulasi resources yang diperlukan agar perusahaan berkembang (Moussa 2013b). Executives's slack kuadratik juga menunjukkan corporate governance yang kuat dalam menyelesaikan agency problem dengan memberikan pengawasan dan mempersempit peluang bagi manajemen yang akan melakukan tindakan yang merugikan principal karena akan diawasi oleh manajemen lainnya.

Discretionary current accruals sebagai kualitas pelaporan kuangan memberikan pengaruh negatif terhadap hubungan antara cash reserves slack dengan nilai perusahaan perdana. Hasil ini mendukung penelitian Sun et al. (2012) yang menunjukkan bahwa cash reserves slack dari kualitas pelaporan keuangan yang rendah memperparah agency problems dan investor memandang cash reserves slack tidak digunakan untuk investasi proyek yang menghasilkan net present value positif melainkan sebagai kamuflase atas kondisi keuangan 
perusahaan yang sebenarnya. (Chung, Firth \& Kim 2005) serta cash reserves slack berpotensi untuk disalahgunakan manajemen untuk kepentingan pribadinya.

\section{Saran}

1. Bagi perusahaan yang akan melakukan IPO disarankan untuk memperhatikan besaran slack resources yang optimal dalam meningkatkan nilai perusahaan saat IPO.

2. Bagi investor, dalam menilai perusahaan saat IPO sebaiknya investor juga mempertimbangkan jumlah direksi dan komisaris.

3. Dikarenakan keterbatasan data, penelitian selanjutnya perlu menggunakan sampel yang lebih banyak dengan menggunakan pengukuran slack resources yang datanya lebih banyak tersedia di prospektus.

4. Penelitian lebih lanjut juga perlu dilakukan terkait bentuk financial slack lainnya yang dapat mempengaruhi nilai perusahaan saat IPO Pengukuran lain nilai perusahaan perdana selain IPO Proceeds perlu dijadikan pertimbangan serta pengukuran experience slack disarankan menggunakan industry-specific experience untuk mengcapture pengalaman spesifik manajemen. Data primer juga disarankan untuk penelitian lebih lanjut.

5. Bagi akademisi, penelitian lebih lanjut perlu dilakukan dengan menggunakan atribut gabungan dari kualitas pelaporan keuangan untuk melihat variabel kualitas pelaporan keuangan secara keseluruhan dan bagaimana pengaruhnya dalam memoderasi financial slack terhadap nilai perusahaan perdana.

\section{Daftar Referensi}

Aktas, N.; Crocci E.; dan Petmezas D. (2015). Is working capital management value-enhancing? evidence from firm performance and investments. Journal of Corporate Finance.

Andrews, A. O., \& Welbourne, T. M. (2000). The people/performance balance in IPO firms: the effect of the Chief Executive Officer's financial orientation. Entrepreneurship Theory and Practice, 25, 93.

Bourgeois III, L.J. (1981). On the measurement of organizational slack. The Academy of Management Review, 6, 29-39.

Certo, S. T., Daily, C. M., \& Dalton, D. R. (2001b). Signaling firm value through board structure: an investigation of Initial Public Offerings. Entrepreneurship Theory and Practice, 26, 33.

Chung, R., Firth, M; \& Kim , J.B. (2005). Free cash flow agency costs, earnings management, and investor monitoring. Corporate Ownership and Control, 2, 51-61.

Cyert, R. M., \& March, J. G. (1963). A behavioral theory of the firm. Englewood Cliffs, NJ: Prentice-Hall. 
Deeds, D. L., Decarolis, D., \& Coombs, J. E. (1997). The impact of firm-specific capabilities on the amount of capital raised in an Initial Public Offering: evidence from the biotechnology industry. Journal of Business Venturing, 12, 31.

DuCharme,L.L., Malatesta, P.H. dan Sefcik, S.E. (2000). Earning management: IPO valuation and subsequent performance.

George, G. (2005). Slack resources and the performance of privately held firms. Academy of Management Journal, 48, 661-676.

Gulati, R., \& Higgins, M. C. (2003). Which ties matter when? The contingent effects of interorganizational partnerships on IPO success. Strategic Management Journal, 24, 127.

Hambrick, D. C., \& D'Aveni, R. A. (1988). Large corporate failures as downward spirals. Administrative Science Quarterly, 33, 1-23.

Ibbotson, R. (1975). Price performance of common stock new issues. Journal of Financial Economics, 2, 235272.

Kor, Y. Y., Mahoney, J. T., \& Michael, S. C. (2007). Resources, capabilities and entrepreneurial perceptions. Journal of Management Studies, 44, 1187-1212.

Kraatz, M. S., \& Zajac, E. J. (2001). How organizational resources affect strategic change and performance in turbulent environments: theory and evidence. Organization Science, 12, 632-657.

Lie, E. (2000). Excess funds and agency problems: an empirical study of incremental cash disbursement. Review of Financial Studies, 13, 219-248.

Ljunqvist, A. (2005). IPO underpricing. Handbook of Empirical Corporate Finance, 2, 375-422.

Miller, K. D., \& Leiblein, M. J. (1996). Corporate risk-return relations: returns variability versus downside risk. Academy of Management Journal, 39, 91-122.

Mishina, Y., Pollock, T. G., \& Porac, J. F. (2004). Are more resources always better for growth? resource stickiness in market and product expansion.” Strategic Management Journal, 25, 1179-1197.

Moses, O. D. (1992). Organizational slack and risk-taking behaviour: tests of product pricing strategy. Journal of Organizational Change Management, 5, 38.

Mousa, Fariss-Terry. (Mei 2009) When do slack resources impact new venture success?. College of Business Washington State University Dissertation.

Moussa, Fariss-Terry; Marlin, D.\& Ritchie W.J. (2013a). Configurations of slack and their performance implications: an examination of high-tech IPOs. Management Decisions, 51, 225-247

Moussa, Farris-Terry \& Reed, R. (2013b). The impact of slack resources on high-tech-IPOs. Entrepreneurship: Theory and Practice, 37, 1123-1147.

Myers, Stewart C. \& Rajam. (1998). The paradox of liquidity. Quarterly Journal of Economics, 108, 733-771.

Newbert, S. L. (2007). Empirical research on the resource-based view of the firm: an assessment and suggestions for future research. Strategic Management Journal, 28, 121-146.

Nohria, N., \& Gulati, R. (1996). Is slack good or bad for innovation?. Academy of Management Journal, 39,1245-1264.

Penrose, E. (1959). The Theory of the Growth of the Firm: Oxford

Sembel, Roy H.M. (1996) IPO anomalies, truncated excess supply,and heterogenous information. J.M. Katz Graduate School of Business Dissertation, University of Pittsburgh, Pennsylvania. 
Sun, Q., Yung, K., \& Rahman, H. (2012). Earnings quality and corporate cash holdings. Accounting and Finance, 52, 543-571.

Thompson, J. D. (1967). Organizations In Action. New York: McGraw-Hill.

Tykova, T. (2006). IPO and earnings management in Germany, dalam Initial Public Offerings in International Prespective, Gregorio, G. (Editor). USA: Butterworth-Heinemann.

Woodman, R. W., Sawyer, J. E., \& Griffin, R. W. (1993). Toward a theory of organizational creativity. Academy of Management Review, 18, 293-321.

Zimmerman, M. A. (2008). The influence of top management team heterogeneity on the capital raised through an initial public offering. Entrepreneurship Theory and Practice, 32, 391. 